\title{
User Experience for Person with Disabilities
}

\author{
Mona Deshmukh \\ Assistant Professor, MCA \\ VESIT, Chembur, \\ Mumbai, India
}

\author{
Dhanashri Phatak \\ Department of MCA \\ VESIT, Chembur, \\ Mumbai, India
}

\author{
Bhagyesh Save \\ Department of MCA \\ VESIT, Chembur, \\ Mumbai, India
}

\begin{abstract}
At a day and age where the sky is the limit; technology is one of the basic needs, it is high time that this technology be accessible to all. Websites are used by people almost every day. One would think that this will lead to the development of more websites keeping in mind the needs of not just the average human being but also specially-abled people, but that is sadly not the case. Digital properties are usually built for people with no disabilities. Most businesses perhaps don't see any value in serving a tiny minority of differently abled people. Enhancing the user experience and adding features that are useful for a perfectly abled person would ensure more business to a company than spending more time and resources on complying accessibility guidelines. [1] Technology, especially, the internet can be of great use to differently-abled people and can make their life simpler. We have considered the ease for people with special needs when constructing buildings, roads and malls, it is about time we do the same when it comes to technology. This paper lists the importance of user experience in making websites, applications etc. more accessible to people with disabilities. It also reviews the work done on this area till date.
\end{abstract}

\section{General Terms}

User Experience, User Interface, Visually Impaired, Accessible Applications.

\section{Keywords}

UX, UI, Disability, Accessibility, Adaptability, Assistive.

\section{INTRODUCTION}

User experience is a broad term that covers a wide variety of application areas. In layman terms, user experience is nothing but how easy an application is for a user to use. It will take into account the number of clicks to get a work done in an application, the visual appeal, the readability, the easy traversal and many other aspects of a website or a web application. In software development, just delivering a project that fulfills the user requirement or business goal is not enough. The acceptance of an end product will also depend on the quality of the user' interaction with the system. The client might have some perception as to how their end product looks and it is the developers' task to fulfill as much as they can of this demand.

Peter Moville represents this through his User Experience Honeycomb. [2] It includes following seven things to provide meaningful and best quality of user experience.
1. Useful: The content which you are going to use should fulfil user's requirement and original.

2. Usable: The site mute be easy to understand for the user.

3. Credible: Content of website must be trustworthy.

4. Desirable: Pictures, brand, and other visual elements are used to generate emotion and feelings.

5. Findable: The content included should be understandable, easy to navigable and locatable.

6. Accessible: The content needs to be accessible to disabled people.

7. Valuable: Your system or product should give or add some value in user's life. Then the user will use your product otherwise it is useless to the customer.

The user interface plays a major role in the user experience and also in the success or failure of an application. A good user interface design attracts users' towards. The user interface is the users' first interaction with the application and the most lasting one. For. e.g. an ATM can fulfill it functionality of dispensing cash, but the ease with which the user can operate the machine is determined by its user interface and in turn affects the users' opinion of returning to the ATM or not. It can be as simple as choosing the right color which can please a user. Jakob Nielsen and Rolf Molich gives us ten user interface guidelines [3] to design software with your user's needs and expectations in mind. All this considering that the user has no special needs. The considerations while creating a good user interface are very different when catering to the needs of the disabled.

\section{TOPIC BACKGROUND}

In the world, there are almost $10 \%$ people are disabled. Disability can be of any type such as vision impairment, deafness, mental health conditions, intellectual disability, Autism Spectrum disorder, physical disability and others. These are the conditions which come by birth, but there are also some other types of disability which can come into picture after birth such as, acquired brain injury, an illness, the ageing process or because of some accident. Disable people have to rely on technology which is designed for them which are very few in number. There are some technologies specifically designed for them, such as Braille text for people with visual impairment and text telephones (TTY) for people with hearing disability.

Recently, technology shifted from analogue to digital, since digital information can easily be converted into text, voice or physical patterns. Technology that improves the accessibility of people with the disability falls into the following three categories. 


\subsection{Assistive Technology}

Assistive Technology [4] can be anything which will increase the functionality or capability of a person with a disability. It can be an item, equipment, program, application. Assistive technology can be low-tech, high-tech, computer hardware, computer software or specialized curricular software. It includes some of the things like communication boards, special purpose computer, special switches, keyboards, wheelchairs, braces, electronic devices and much more. Assistive technology helps people who have a different type of disabilities. The technology differs depending on the type of disability. There are people who are trained professionals and consultants in this type of technology.

\subsection{Adaptive Technology}

Adaptive technology [5] is something which improves the ability of a disabled person. So that disabled people can perform the same task with the same efficiency. Adaptive technology helps to remove the gap between disabled and normal people. Technology has improved so much that visually impaired people can access, transmit, store, and process the information same as sighted people do. There are five important methods that can render output from computer or printer which can be read by visually impaired or blind people such as Electronic braille displays, Braille Printer, Screen Reader, text magnification and reading device. Some of the examples are as follows.

\section{Screen Reader}

Screen reader converts computer output into major spoken languages. With the help of screen reader, a blind person can use the computer to send mail, search something on google or write letters.

\section{Braille Embossers}

It is a hardware device which is similar to a printing device the only difference is it will print the document in Braille.

\section{USER EXPERIENCE}

User Experience can be termed as the emotion or bonding between the application and users. If user experience is great then the more user will use that application.

\subsection{Why Accessibility?}

"Accessibility is defined as the matching of delivery of information and services with user's individual needs and preferences in terms of intellectual and sensory engagement with resources containing that information or service, and their control of it. Accessibility is satisfied when there is a match regardless of culture, language or disabilities." [6]

As the online environment is an extension of the actual one, there is nothing more effective than a metaphor with the offline world to understand how crucial accessibility online can affect your business.

Consider, you have started new business, setup new store in the center of the city at very good location, easily accessible by people with large display windows, all the items kept for sale are properly organized and have proper description, and also you welcome and help customer with gentle attitude.

Now consider same business but, there is large step that makes it difficult to enter your store. There are no display windows, all the items kept for sale are scattered and have no description at all. You don't bother about customer's requirement and treat them rudely.
Customer chooses first above the other one, same things happens with online world.

If your website or application is not properly accessible for people you will lose your potential customer as well as business.

\subsection{Nielsen and Molich's User Interface Design Guidelines}

Nielsen and Molich's 10 User Interface Design Guidelines

\section{Visibility of system status}

The user should always know the status of the system and it should be easily visible. It should be easy to understand and displayed on the screen within a reasonable amount of time.

\section{Match between system and the real world}

Your software objects and concept should match to the realworld object based on the targeted users. The likeliness to the real-world scenarios makes systems easier to use.

\section{User control and freedom}

Offer user with backwards functionality such as undoing and redoing things.

\section{Consistency and standards}

The designer should maintain the terminology and graphic elements used throughout the software.

\section{Error prevention}

Try to design a system with minimal errors. Users don't like being called upon to detect and remedy problems.

\section{Recognition rather than recall}

The designer should minimize the load by keeping taskrelevant information on the user's screen. Human is capable of maintaining only five items in short-term memory at a time. So, designer should ensure that user recognizes the functionality rather than recalling it. Recognizing is easier than recall. For example, we find multiple choice questions easier than short answer questions.

\section{Flexibility and efficiency of use}

As use increases, software demands less interaction with faster navigation. The user should able to customize the interface according to their need.

8. Aesthetic and minimalist design

Software should have minimal clutter. On display, only necessary things should be there.

\section{Help and documentation}

The designer should always provide with help documentation which will be easy to locate. Documentation is necessary, whether the user finds the system easy to understand or not. It should guide user the way he wants with ease to solve the problem they are facing.

10. Help users recognize, diagnose and recover from errors The user won't be a technical person. So, the designer should keep error message as simple as possible and in plain text.

\subsection{Benefits of Accessible Website}

Accessible website or application has great benefits that helps you to grow your business.

1. The website will be higher in the search engine results Search Engine Optimization tools and accessibility works same because websites that are inaccessible to users with disabilities are also inaccessible to search engines tools. The most powerful element of Search Engine Optimization tool is creating machine-readable content so that these content can be 
read by users as well as assistive technologies, like screen readers etc.

\section{Protection from Law}

According to the Disability Discrimination Act and Equality Act 2010 service providers must not discriminate against disabled people and an equal access to public or private services should be guaranteed.

\section{Increasing Popularity}

An accessible website will be not just usable for all users but also for people with disabilities. Great usability and a positive user experience on your website will increase popularity of website.

\section{Your business will gain a positive image.}

\subsection{Guidelines to Follow}

Web Content Accessibility Guidelines 2.0 was defined in 2008. It is an internationally adopted technical standard; the standard guides service providers to solve many of the problems that your users with disabilities face on the web. Although, WCAG 2.0 does not cover all of the issues that users with disabilities might face, they are internationally recognized standards. [7]

1.1.Perceivable: The principle of a website being perceivable is about the senses like sight or hearing, people use when using the web,

1.1.1. Provide text alternatives for non-text content, e.g. Image Description

1.1.2. Include captions and other alternatives for multimedia to understand them easily.

1.1.3. Create content such that it can be published in different ways, which includes assistive technologies, without losing its meaning.

1.1.4. It should be easier for users to view and hear content.

1.2. Operable: The actions people perform when using website:

1.1.1. Make each and every functionality available from a keyboard.
1.1.2. Provide enough time to users for reading and using content.

1.1.3. Do not include element that causes seizures.

1.1.4. Make user's navigation easier.

1.3. Understandable: Your website must contain clear terms and statements and have simple instructions:

1.1.1. Make text easy to read and understandable

1.1.2. Make content appear in predictable manner

1.4.Robust: A robust website is one that third-party technology can rely on. This minimizes the risk of your users relying on technology that cannot correctly process your website:

1.1.1. Maximize compatibility with current and future user tools.

WCAG 2.0 are organized into three levels of conformance:

1. Level $A$ - The least web accessibility features.

2. Level $A A$ - Configured for most common issues for disabled users.

3. Level $A A A$ - The most complex level of web accessibility.

\subsection{Statistics}

According to the World Health Survey conducted by World Health Organization, around $15.6 \%$ people i.e. 785 million persons, 15 years and older live with a disability, while the Global Burden of Disease estimates $19.4 \%$ of people i.e. around 975 million people do. Of these, the World Health Survey estimates that $2.2 \%$ i.e. 110 million people have very significant difficulties in functioning, while the Global Burden of Disease estimates that $3.8 \%$ people i.e. 190 million have "Severe Disability". This number is continuously increasing as population is growing. [8]

According to survey conducted by WebAIM [16] to understand preference and problems faced by disabled people. People over the world replied to this survey, and after the analysis of the responses received following charts has been prepared.

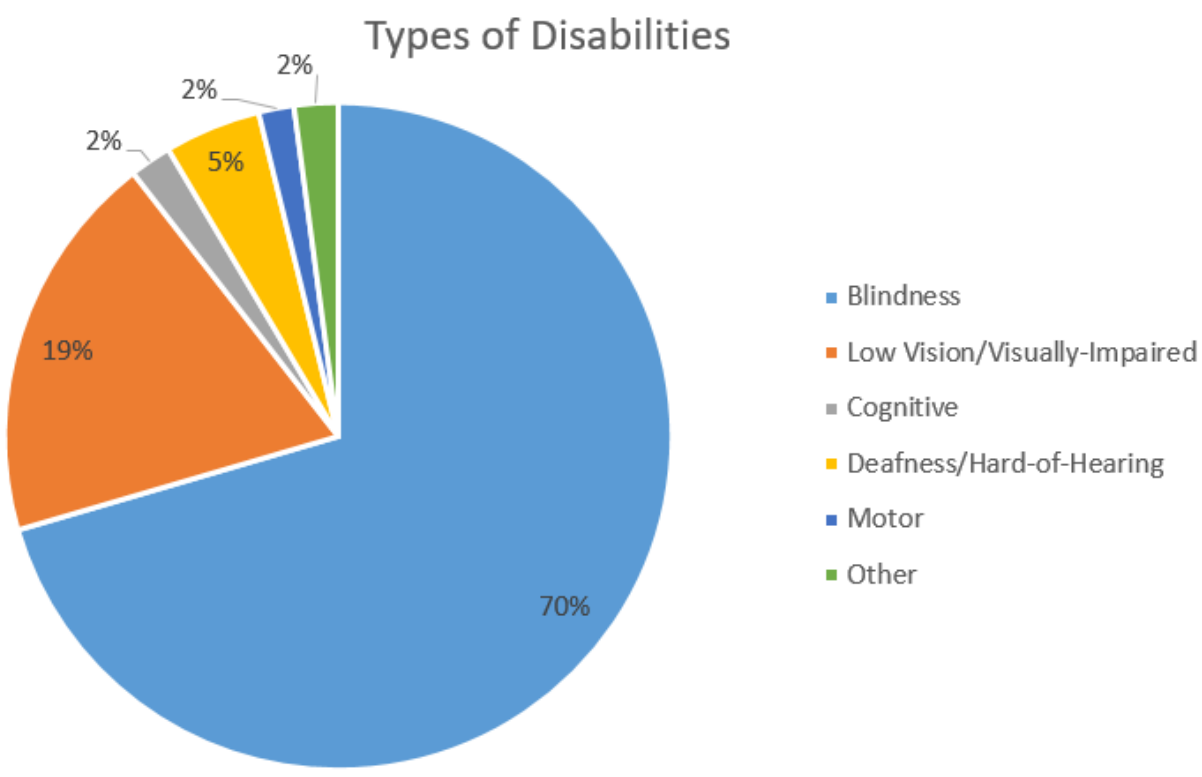

Fig 1: Types of Disabilities 


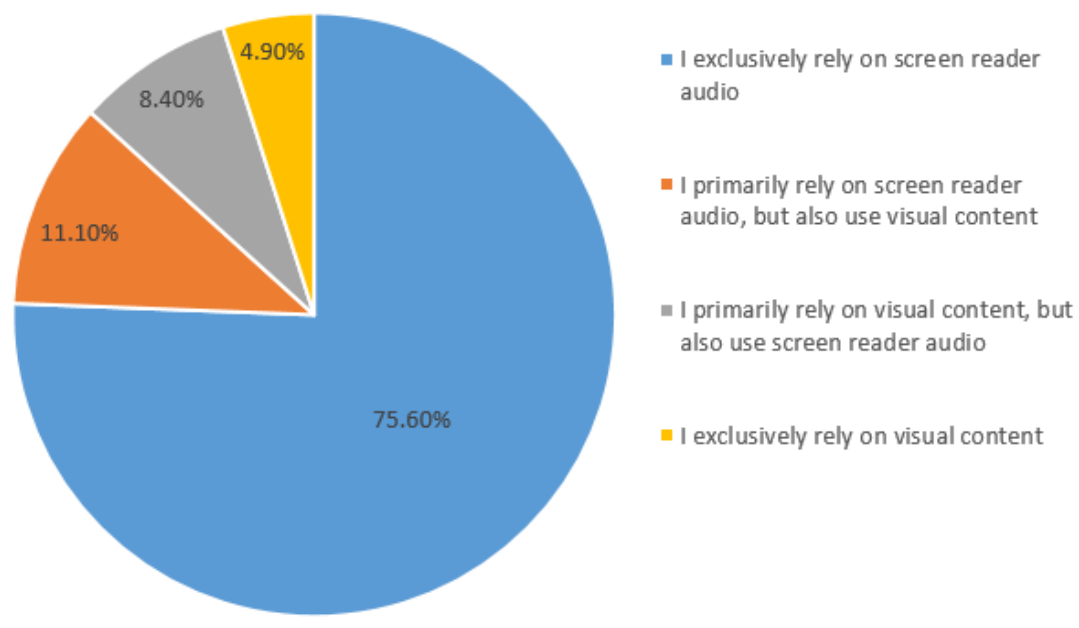

Fig 2: Screen Reader Usage

\section{In general, how accessible are social media web sites to you?}

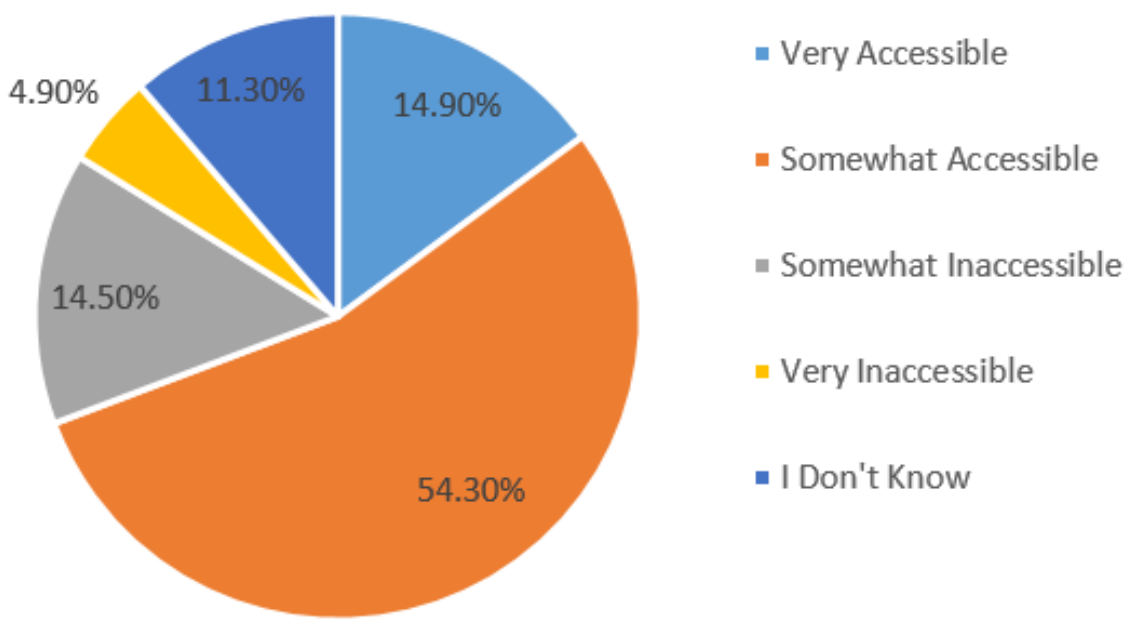

Fig 3: Social Media Accessibility

\section{ACCESSIBILITY TECH TOOLS}

There are several tools available that helps disabled person for accessing web or other applications.

Web Access Tools for people with Visual Disabilities

1. Screen Readers: It is a software tool that reads out text on the screen with a speech synthesizer or translates it into Braille, e.g. COBRA [9]. COBRA screen reader technology provides a way for visually impaired people to easily control what is read, such as by finding strings of text on the screen, reading just a line of text, or reading just text highlighted. Some other popular screen readers include: Hal [10], JAWS [11] etc.

2. Braille Keyboards: A Braille keyboard is specially designed for blind people. It's very different than a standard keyboard. There are 8 keys which are used to compose the Braille letters. Braille keyboards are made in a way such that navigation and locating the cursor is much easier for blind people.

3. Screen Magnifiers: Screen magnifying technology magnifies text or content of website. It helps people who are not blind but has weaker eyesight, to view information on a computer screen. There are numerous types of screen magnification technology available, such as Windows Magnifying software. Also, there are some external devices which act like magnifying glasses outside of the screen to advanced software which is installed on the computer. The main objective of screen magnifying technology doesn't just increase the size of the information on the screen but also has functions like reducing glare, increasing contrast, and improving cursor tracking.

4. Refreshable Braille Displays: In this type of Braille keyboard output options are also included. It has small pins which are used to form the Braille letters for 
input/output. A cursor allows the user control to the content of website like, to select which text to translate; the pins are refreshed throughout the reading process. Braille displays are quite expensive but provide great help for people who use the computer a lot, need to speak and type at the same time, or who are deaf-blind and would not be able to use a Screen Reader.

\section{Web Access Tools for people with Physical Disabilities}

1. Sip and Puff Systems: This technology has been adapted to allow people with physical disabilities, such as paralyzed people, to also access the computer and perform task on any system. The device works similarly to a joystick or command stick, but one which is controlled with breath. It recognizes sips or puffs and translates these into commands such as mouse clicks or keyboard characters. [12]

2. Hands-Free Mouse Tracking: There are many ways by which physically-impaired people can control a cursor without having to rely on a mouse or keyboard commands. E.g. FaceMouse [13], which uses a standard web camera that turn your head movements into a mouse operator. It does this by recognizing face or head movements and translating them into commands, like clicks. You can use your head movements as a joystick. FaceMouse even lets users set certain movements to certain commands, like "Open Mouth" to "Enter Key."

3. Lomak Keyboard [14]: It is a light-operated mouse and keyboard. A small device with a laser pointer is fitted on the head of the user. By moving the head to point the laser light at various points on the keyboard or screen, users can control the cursor and operate on system. The Lomak keyboard has an option for voice-controlled confirmation of commands.

4. Eye Gaze Edge System [15]. This system works by having a specialized video camera fitted below the screen. The video camera monitors the user's eyes movement to determine where the user is looking. The user then operates the system by looking at special keys which are displayed on the control screen for providing additional input if required

5. Voice Controls: Voice control software includes programs which understand and analyzed voice command then convert them to Text, and also allow you to command the computer with your voice.

\section{CONCLUSION}

As seen in the survey, a lot of people rely on screen readers and it is imperative that user accessibility be considered when building a website. It will be helpful to a lot of users and will help with the popularity of the website. It will also improve the traffic in the websites and add to the revenue generated by it.

Though there are laws and development standards in place that ensures that people with disabilities be treated with the same empathy and consideration as the average human being, it is not known to the wider public which includes developers and organizations. We are still lacking in creating a good and interactive user experience for disabled people. As the number of disabled people is increasing day by day, need for accessible systems or application becomes the must.

The number of inaccessible websites is far more than the accessible websites. Most of the application used nowadays are designed considering only normal people, so it has become difficult for disabled people to access them. Seeing the way web technology is ingraining itself into our day to day life, it is high time we look at development of a website from all possible sides.

\section{ACKNOWLEDGMENTS}

We are grateful to all the faculty members of the Master of Computer Applications Department of V.E.S. Institute of Technology (VESIT), Mumbai for their continuous support and valuable suggestions.

We express our thanks to all our colleagues who constantly supported us without any hesitation and encouraged us during the course of our project work.

Lastly and most importantly, we are grateful to our parents for their unconditional love, constant encouragement and reassurance which gave us the strength to complete this project.

\section{REFERENCES}

[1] Accessibility Part 1: Designing with Empathy for Better Accessibility, [online] Available at https://www.srijan.net/blog/part-1-designing-empathybetter-accessibility [Accessed January 4, 2017]

[2] Usability.gov. (2018). User Experience Basics Usability.gov. [online] Available at: https://www.usability.gov/what-and-why/userexperience.html [Accessed 16 Apr. 2018].

[3] The Interaction Design Foundation. (2018). What is User Interface (UI) Design?. [online] Available at: https://www.interaction-design.org/literature/topics/uidesign [Accessed 12 Apr. 2018].

[4] Assistive Technology Industry Association. (2018) What is AT? - Assistive Technology Industry Association. [online] Available at: https://www.atia.org/at-resources/what-is-at/ [Accessed 17 Apr. 2018].

[5] Www3.sympatico.ca. (2018). WHAT IS ADAPTIVE TECHNOLOGY. [online] Available at: http://www3.sympatico.ca/tamru/resource/what.html [Accessed 17 Apr. 2018].

[6] User experience design, ux and usability blog keepitusable. (2018). visually impaired Archives - user experience design, ux and usability blog - keepitusable. [online] Available at: http://www.keepitusable.com/blog/tag/visually-impaired/ [Accessed 17 Apr. 2018].

[7] W3.org. (2018). Web Content Accessibility Guidelines (WCAG) 2.0. [online] Available at: https://www.w3.org/TR/WCAG20/ [Accessed 17 Apr. 2018].

[8] Whqlibdoc.who.int. (2018). World report on disability. [online] Available at: http://whqlibdoc.who.int/hq/2011/WHO_NMH_VIP_11. 01_eng.pdf?ua=1 [Accessed 17 Apr. 2018].

[9] Bayareadigital.us. (2018). Cobra: Screen Reader with Braille, Speech and Magnification. [online] Available at: http://www.bayareadigital.us/products/baum/cobra.html [Accessed 17 Apr. 2018].

[10] Yourdolphin.com. (2018). Hal - Now the most popular Arabic Screen Reader. [online] Available at: https://yourdolphin.com/news?id=154 [Accessed 17 Apr. 2018] 
[11] Freedomscientific.com. (2018). JAWS Screen Reader Best in Class. [online] Available at: http://www.freedomscientific.com/Products/Blindness/J AWS [Accessed 17 Apr. 2018]

[12] Corp., O. (2018). Sip/Puff Switch. [online] Orin.com. Available at: http://www.orin.com/access/sip_puff/ [Accessed 17 Apr. 2018].

[13] Facemouse.it. (2018). FaceMOUSE , l'originale: mouse per disabili, tastiera,comunicatore. [online] Available at: http://www.facemouse.it/ [Accessed 17 Apr. 2018].
[14] Guides.lomakkeyboard.com. (2018). Lomak. [online] Available at: http://guides.lomakkeyboard.com/en/lmqs01.html [Accessed 17 Apr. 2018].

[15] Eyegaze.com. (2018). Eye Tracking | Advanced EyeTracking Technology by LC Technologies. [online] Available at: http://www.eyegaze.com/ [Accessed 17 Apr. 2018].

[16] Webaim.org. (2018). WebAIM: Screen Reader User Survey \#7 Results. [online] Available at: https://webaim.org/projects/screenreadersurvey7/ [Accessed 16 May 2018]. 